\title{
Distal Interphalangeal Joint
}

National Cancer Institute

\section{Source}

National Cancer Institute. Distal Interphalangeal/oint. NCI Thesaurus. Code C101529.

Interphalangeal joint located between the second and third phalanges. 